second world,

second sex 


\section{second world,}

Kristen Ghodsee second sex 
Socialist Women's Activism and

Global Solidarity during the Cold War 
๑) 2018 DUKE UNIVERSITY PRESS. All rights reserved Printed in the United States of America on acid-free paper $\infty$ Designed by Courtney Leigh Baker

Typeset in Warnock Pro and Helvetica Neue by Copperline Books

Library of Congress Cataloging-in-Publication Data

Names: Ghodsee, Kristen Rogheh, [date] author.

Title: Second world, second sex : socialist women's activism and global solidarity during the Cold War / Kristen Ghodsee.

Description: Durham : Duke University Press, 2019. | Includes bibliographical references and index.

Identifiers: LCCN 2018026169 (print) | LCCN 2018029608 (ebook)

ISBN 9781478003274 (ebook)

ISBN 9781478001393 (hardcover : alk. paper)

ISBN 9781478001812 (pbk. : alk. paper)

Subjects: LCSH: Women's rights-International cooperation-

History-2oth century. | Feminism - International cooperation-

History-2oth century. | Women political activists-History-2oth

century. | International Women's Year, 1975. | International Women's

Decade, 1976-1985. | Women and socialism. | Women-Political

activity-Bulgaria. | Women-Political activity-Zambia.

Classification: LCC JZ1253.2 (ebook) | LCC JZ1253.2 .G47 2019 (print) |

DDC 305.4209171/709045-dc23

LC record available at https://lccn.loc.gov/2018026169

Cover art: Course participants in the WIDF-CBWM School for Solidarity, Bulgaria, 1980. 
For Elena Lagadinova

and Irene Tinker 